\title{
UMA REFLEXÃO SOBRE O PROJETO UM COMPUTADOR POR ALUNO - UCA
}

\author{
Antonio Carlos C. Marques ${ }^{1}$, Andreia de Jesus ${ }^{2}$ \\ ${ }^{1}$ Secretaria de Estado da Educação \\ Curitiba - PR - Brazil \\ ${ }^{2}$ Coordenação de Sistemas de Informação \\ Faculdades Integradas do Brasil (UniBrasil) - Curitiba, PR - Brazil \\ amarques@seed.pr.gov.br, sistemas@unibrasil.com.br
}

\begin{abstract}
This paper aims to make a critical reflection of driving One Laptop per Student Project. We started from the premise that computers are an important support for the modernization of the educational system, but have not yet been exploited in all its fullness. The teacher's lack of preparation to the Project is visible and is not meeting the demands. It is clear that digital inclusion in Brazil is still utopian, because few government actions have the purpose of equal opportunities for all citizens. In this way, the practices of the project are far from expected and this requires that the teacher and the set of social actors involved take hold more broadly that instrument (laptop), to evolve in their pedagogical work.
\end{abstract}

Resumo. Este artigo tem como objetivo fazer uma reflexão crítica da condução do Projeto Um Computador por Aluno - UCA. Partiu-se da premissa de que os computadores são um importante apoio para a modernização do sistema educacional, mas ainda não foram aproveitados em toda sua plenitude. A falta de preparo dos professores para o Projeto UCA é visível e não está atendendo às demandas, deixando claro que a inclusão digital no Brasil ainda é uma utopia, pois poucas ações do Governo têm a finalidade da equiparação de oportunidades a todos os cidadãos.Desse modo, as práticas do Projeto UCA estão bem longe do esperado e isso exige que o formador e o conjunto de atores sociais envolvidos se apoderem mais amplamente desse instrumento, para evoluir em seu trabalho pedagógico.

\section{Introdução}

As tecnologias de informática e telecomunicações representam um salto de dimensões ainda desconhecidas e de mudanças sem precedentes nos processos de ensino e aprendizagem. Neste sentido, os computadores chegam às escolas como importante apoio para a modernização do sistema educacional. Além disso, o aporte das tecnologias na educação tem proporcionado um novo pensar no processo de ensino e aprendizagem. Contudo, o sistema educacional brasileiro ainda é deficitário, pois as formas de ensinar já não atendem às necessidades de aprendizagem. Mesmo com a introdução das tecnologias nas escolas, há indícios que essa situação pouco se modificou. 
Neste enfoque, prevendo vantagens com a utilização de laptops de baixo custo na sociedade brasileira, o governo vem fomentando um projeto de inclusão digital direcionado à comunidade escolar que atenda os objetivos de uma educação básica inclusiva e de qualidade para todos. Com isso, o Projeto Um Computador por Aluno UCA tem como objetivo propiciar o desenvolvimento científico e tecnológico por meio da expansão do conhecimento, a fim de permitir a emancipação individual e coletiva, a consolidação da democracia, a melhoria da qualidade de vida e a equidade social amparada em valores éticos, estéticos e solidários (Brasil, 2007).

Acredita-se que as inovações proporcionadas pelo projeto UCA, certamente poderão promover mudanças fundamentais nas perspectivas das escolas e dos professores, especialmente por estimulá-los a encontrar seus próprios caminhos para melhorar o ensino, para garantir a aprendizagem dos alunos e o desenvolvimento de projetos sustentáveis de inovação.

Levando em consideração esses aspectos, o objetivo desse artigo é fazer uma reflexão crítica do Projeto UCA em contraponto com a formação dos professores para o uso de Tecnologias de Informação e Comunicação nas atividades escolares, utilizando-se de material bibliográfico a respeito do assunto.

\section{As Mudanças na Educação por conta das Tecnologias de Informação e Comunicação}

As Tecnologias de Informação e Comunicação (TICs) podem facilitar a vida do homem em suas tarefas cotidianas. Atualmente, as tecnologias estão em toda parte, atingindo todas as atividades humanas. Por conta das tecnologias, as ocupações se transformaram, algumas desapareceram, enquanto outras tantas surgiram que, até então, eram completamente desconhecidas. As TICs transformam as maneiras de se comunicar, de trabalhar, de decidir e de pensar (Sancho \& Hernandez, 2006).

Morin (1995) admite que as tecnologias permitem um novo encantamento na escola, ao abrir suas paredes e possibilitar que os alunos conversem e pesquisam com outros educandos da mesma cidade, país ou do exterior, no seu próprio ritmo. Ainda, Perrenoud (2000) comenta que as TICs podem facilitar o processo interdisciplinar, pois apresentam uma série de vantagens em relação aos métodos convencionais de aprendizagem e facilita a troca imediata de informações, o encorajamento à exploração, maior e menor organização das idéias, maior integração e interação, agilidade na recuperação da informação, maior poder de distribuição e comunicação nos mais variados contextos.

Porém, é importante que as Tecnologias Educacionais ultrapassem o simples ato de adquirir instrumentos de comunicação e utilizá-los no ambiente da escola, ou seja, é necessário trazer para o contexto da escola as informações presentes nas tecnologias e as próprias ferramentas tecnológicas, articulando-as com os conhecimentos escolares e propiciando a interlocução entre os indivíduos. Morin (1995) ainda coloca que os computadores têm facilitado a integração de várias metodologias de ensino, proveniente de diversas mídias que podem ser acessadas tanto em tempo real na escola, como no horário mais favorável a cada indivíduo. 
Projetos como o PROINFO (Brasil, 1997) tem como objetivo principal promover esse desenvolvimento nas escolas, através do uso da telemática como ferramenta de enriquecimento pedagógico. Com isso, busca-se atingir a seguintes metas: melhorar a qualidade do ensino-aprendizagem; possibilitar a criação de uma nova ecologia cognitiva nos ambientes escolares; propiciar uma educação voltada para o desenvolvimento científico e tecnológico; educar para uma cidadania global; valorizar o professor. Contudo, Valente (1999) destaca, em seus comentários sobre o PROINFO, que existe uma preparação inadequada dos professores, em vista dos objetivos de mudança pedagógica propostos por este programa.

Oliveira (2006) também comenta sobre a formação dos professores e coloca que o Estado Brasileiro vem se abstendo cada vez mais dos serviços públicos direcionados ao financiamento da educação e, consequentemente, afeta a formação dos professores, pois recebem pouca instrução. Tendo em vista que a formação docente gira em torno de uma simplificação que valoriza a técnica em si e enfatiza o treinamento para a sua utilização "correta". Nessa perspectiva da substituição das mediações pelos meios, as tecnologias deixam de ser meio auxiliar e passam a ser estruturantes do processo educativo, que são os novos desafios para os professores.

Levando em conta esses aspectos, é necessário rever a formação que está sendo propiciada aos professores, pois o contexto atual da educação aponta mudanças em que sua profissão lhes exige fazer cada vez mais coisas diferentes e ao mesmo tempo. O que se vislumbra é que somente o professor que se disponha a refletir sobre sua ação, planejando e elaborando uma proposta de trabalho comprometida com a qualidade da aprendizagem, poderá ser bem-sucedido e poderá ter condições de utilizar com coerência qualquer recurso tecnológico que se coloque a sua frente. Infere-se que o processo de formação necessário para o professor deve contemplar não uma acumulação de teorias e técnicas, mas uma formação que articule a prática, a reflexão, a investigação e os conhecimentos teóricos requeridos para promover uma transformação na ação pedagógica. Ou seja, o papel do professor frente às tecnologias modifica-se de "entregador" da informação como era antes, para o de facilitador, supervisor e consultor do aluno em seu processo de resolver os problemas (Valente, 1999).

Para tanto, é necessário mudanças profundas na escola, pois os modos de conceber o ensino e a aprendizagem supõem uma nova atitude por parte dos professores, dos alunos e de toda a equipe escolar. Logo, um olhar sobre esses referenciais nos remetem a outra investigação, que é o de analisar as indefinições do Projeto Um Computador por Aluno - UCA.

\section{Aspectos Basilares do Projeto Um Computador por Aluno - UCA}

O Projeto UCA, como já mencionado, tem como finalidade o desenvolvimento tecnológico, dirigido para o progresso e a expansão do conhecimento. Esse projeto conta com alguns pontos inovadores. O primeiro deles é o uso do laptop por todos os estudantes e educadores da escola pública em um ambiente que permita a imersão numa cultura digital. Também propicia mobilidade de uso do equipamento em outros ambientes dentro e fora da escola. Permite conectividade, pela qual o processo de utilização do laptop e a interação entre estudantes e professores se darão por meio de redes sem fio conectadas à internet. Além disso, proporciona o uso pedagógico das diferentes mídias colocadas à disposição no laptop educacional. 
O equipamento utilizado para o Projeto UCA possui largura e altura nas dimensões de uma folha de papel A4 $(21 \times 29,7 \mathrm{~cm})$, tela de cristal líquido (LCD) e dispositivos de segurança adequados. O equipamento permite acesso ao Programa de Formação Continuada em Mídias na Educação, tem baixo consumo de energia e autonomia suficiente para garantir o uso integral durante os turnos da escola. $\mathrm{O}$ equipamento permite a reprodução de sons, vídeos, conexão com máquinas fotográficas digitais, filmadora digital, gravador de voz e vídeo (Brasil, 2007).

O Coordenador do Projeto UCA é o Governo Federal, que deve prover os recursos financeiros necessários para a aquisição e distribuição dos equipamentos; executar o processo de aquisição dos mesmos; facilitar sua instalação física nas escolas públicas; oferecer a formação dos profissionais da educação articulados com os estados, municípios e instituições de ensino superior. Os governos estaduais e municipais devem assegurar que a adesão formal ao projeto seja inserida nas políticas educacionais locais, o que compreende os compromissos políticos assumidos com vistas à continuidade da implementação do projeto UCA.

A metodologia da formação para o projeto engloba três dimensões que se complementam em seu desenvolvimento. A primeira delas abrange a dimensão tecnológica que diz respeito à apropriação e domínio dos recursos tecnológicos voltados para o uso do sistema Linux Educacional. A segunda é a pedagógica que se refere ao uso dos laptops nos processos de ensinar e aprender, bem como na gestão de tempo, espaço e relações entre os protagonistas da escola, do sistema de ensino e da comunidade externa. A terceira dimensão é a teórica, que busca a articulação de teorias educacionais que permitam compreender criticamente o uso em diferentes contextos e reconstruir as práticas pedagógicas e de gestão da sala de aula e da escola (Brasil, 2007).

Já a formação de professores do UCA compreende, em sua primeira etapa, a apropriação tecnológica, através do Linux Educacional, aplicativos do laptop e ambiente virtual. Num segundo momento, ocorre a introdução ao Projeto UCA e planejamento da formação na escola. Na sequência, ocorre a formação dos educadores e acompanhamento das atividades de uso pedagógico do laptop e, em seguida, é feita uma proposta de ação e elaboração do Projeto UCA na escola. Por último, é feito um seminário para apresentação dos resultados, análises com base em documentos e nas apresentações do projeto UCA.

Logo, é possível verificar que a complexidade de execução do UCA é bastante grande, pois para o seu sucesso é necessário ir além da disponibilização dos equipamentos e da alfabetização digital (conhecimentos técnicos de utilização dos equipamentos) de seus usuários. É necessário trabalhar o letramento digital (utilização adequada e visão crítica de uso desses equipamentos) com professores e alunos, para que a inclusão digital através desse projeto seja sustentável.

\section{Críticas ao Projeto UCA}

A proposta de implantação do projeto UCA teve início em 2007 com a Fase I, a qual tinha como objetivo a experimentação do laptop em cinco escolas distribuídas nos estados do Rio de Janeiro, Rio Grande do Sul, São Paulo, Tocantins e Distrito Federal. Além disso, no final deste ano, o Ministério da Educação concluiu o pregão para comprar os equipamentos, mas um pedido de visto do Tribunal de Contas da União 
(TCU) atrasou a fase de testes e, consequentemente, as metas estabelecidas para 2008. Logo, os laptops começaram a chegar às escolas em 2009, cuja previsão era distribuir equipamentos em 300 escolas espalhadas por 278 municípios. Desde então mais de 300 escolas já foram contempladas com o projeto.

Os resultados nestas escolas têm sido positivos, pois aumentou a participação de pais e alunos no processo. O Coordenador de Inclusão Digital da Presidência da República já afirmava que o objetivo do programa não se restringe à inclusão digital dos alunos e professores, mas abrange uma reformulação dos padrões em sala de aula. E ainda reforça (Cieglinski ,2009): "Não é uma visão tecnológica, mas de um instrumento para reformar e até revolucionar o processo pedagógico, que está em crise, por conta da desmotivação de professores e alunos".

Embora a iniciativa do UCA seja bem definida, ainda há vários percalços a serem superados, dentre eles a burocracia dos órgãos governamentais que acaba atrasando os processos necessários para a compra dos equipamentos e, também, muitas vezes, a falta de ética em alguns direcionamentos dados na execução das atividades do projeto. Outro entrave, com certeza, é a questão pedagógica de uso dessas tecnologias. Conforme coloca Papert (1997), o problema é encontrar meios através dos quais os professores possam ser amparados, em função das mudanças que a inserção dos computadores nas escolas traz às práticas pedagógicas.

O professor Marcos Meier, em entrevista para Junior (2008), revela que mesmo com toda a tecnologia o papel do professor aparece com destaque, pois ele tem mais responsabilidades, embora muitos ainda não estejam preparados e exista um descompasso entre eles e os alunos no que se refere o domínio da tecnologia (computador e internet). Nesta mesma entrevista, o presidente da Associação Brasileira de Tecnologia Educacional (ABT) aponta algumas medidas importantes para superar esse descompasso: (1) modificação do sistema de formação de novos docentes, fazendo deles, orientadores de aprendizagem; (2) requalificação dos atuais professores; (3) instituição de políticas públicas para fornecer, a custo reduzido, equipamentos para os educadores.

Logo, o Projeto UCA deve ser pensado e o professor precisa reinventar sua prática integrando o currículo e todas as suas práticas em uníssono com mais esta tecnologia. Pois, para motivar o educando, o professor precisa desenvolver uma competência didático-pedagógica, epistemológica e relacional, num processo de confiança mútua, suscitando no educando o desejo de aprender e sugerindo a esse a busca pelo saber. Nóvoa (1992) relata que não se trata apenas da reciclagem dos professores para enfrentarem os desafios tecnológicos, mas também, da qualificação para desempenhar novas funções, como administração e gestão escolar, orientação escolar, coordenação pedagógica, dentre outros. Além disso, Valente (1999) comenta que a formação deixa de ser uma simples oportunidade de passagem de informação para ser a vivência de uma experiência que contextualiza o conhecimento que o professor constrói levando em conta as necessidades de seus alunos e os objetivos pedagógicos que se pretende alcançar com o uso das tecnologias.

Em uma pesquisa realizada na primeira escola a implantar o UCA foi possível conhecer as opiniões de professores e alunos sobre o projeto. Os professores entrevistados colocaram que o UCA está promovendo uma inclusão digital no ambiente 
escolar, demandando novas formas de orientar, limitar e organizar o uso do laptop em sala de aula. Ficou claro que o UCA pode trazer um imenso leque de recursos didáticos para os professores para que eles possam atender as necessidades dos estudantes. Para os docentes a escola está diante de um desafio tecnológico e precisa ser repensada. Os professores entrevistados consideram que há um despreparo pessoal e falta de intimidade com o computador, além de desconhecem como utilizar o projeto UCA. No que diz respeito aos alunos, poucos sabem aproveitar o uso dos laptops e deveria haver mais participação e interatividade entre professores e alunos. Isto comprova que as habilidades técnicas que as crianças e adolescentes tem com relação às tecnologias não garante o uso adequado desses recursos. Logo, os alunos também precisam ser orientados de como utilizar as tecnologias da informação e comunicação em suas atividades escolares e em seu processo de construção do conhecimento.

Uma Avaliação de impacto do Projeto UCA deixou claro que os resultados do programa foram sofríveis. O relatório apontou que boa parte dos computadores não foi entregue nos prazos e outros foram entregues sem a infraestrutura necessária para sua adoção em sala de aula. Também, o treinamento dos docentes não deu os resultados esperados. O suporte técnico praticamente é inexistente (Brasil, 2012).

\section{Considerações Finais}

Este artigo teve como objetivo fazer uma reflexão crítica da condução do Projeto Um Computador por Aluno - UCA. Partiu-se da premissa de que os computadores são um importante apoio para a modernização do sistema educacional, mas ainda não foram aproveitados em toda sua plenitude.

Foram comentados problemas que permeiam a trajetória dos computadores em sala de aula, como a formação dos professores que ainda tem sido considerada insuficiente para os dias de hoje, pois eles necessitam de maior preparação para trabalhar com esse novo ambiente educacional que chegou a escola. $\mathrm{O}$ desafio da formação atinge todos os professores, desde os que nunca ligaram um computador, até aqueles que já demonstram destreza no seu uso. O professor precisa ser conscientizado de que os alunos não mais aceitam aprender na forma tradicional e querem uma aula mais rica, na qual o computador tem um papel essencial.

Por sua vez, no UCA parece que a interação entre professor e alunos ainda não se concretizou. É preciso que o professor se disponha a refletir sobre sua ação, planejando e elaborando uma proposta de trabalho comprometida com a qualidade da aprendizagem. Essas reflexões são muito importantes e podem auxiliar na condução do UCA, abrindo caminhos para equacionar os vários problemas que permeiam esse projeto no País.

Conclui-se que a formação dos professores ainda é deficitária para o projeto UCA e isso afeta todo o projeto. Isso ocorre por causa da falta de políticas públicas e o pouco investimento direcionado à formação dos docentes. Assim, o projeto UCA ainda é uma utopia no Brasil e só terá sucesso se os professores realmente estiverem familiarizados na utilização do computador e puderem atender às demandas exigidas. 


\section{Referências}

Brasil. Ministério da educação (2007) "Projeto Um Computador por Aluno (UCA): Reunião de Trabalho", www.proinfo.mec.gov.br

Brasil. Secretaria especial de comunicação social secretaria de pesquisa e opinião pública - Senadores na Mídia - Secretaria de Pesquisa e Opinião. Revista Veja Página Internet. Disponível em: www.senado.gov.br/noticias/opiniaopublica/senamidia/2012/Revistas13.pdf Acesso em: 15 abr. 2012.

Brasil MEC/SEED (1009) "Programa Nacional de Informática na Educação PROINFO - Diretrizes", www.proinfo.mec.gov.br

Cieglinski, Amanda (2009) "Coordenador garante que 150 mil computadores portáteis chegarão às escolas em 2009", www.agenciabrasil.gov.br/noticias/2009/02/13/materia.2009-02-13.9890780212/view

Junior, Luis Celso (2008) "Como Usar a Tecnologia a favor da Educação", www.jornallivre.com.br/128271/tecnologia-e-educacao.html

Morin, Edgar (1995) "As duas globalizações: complexidade e comunicação, uma pedagogia do presente", Porto Alegre: Sulina/EDIPUCRS.

Nóvoa, Antonio (1992) "Formação de professores e profissão docente. In: . Os Professores e a sua formação", Lisboa: Nova Enciclopédia, publicações Dom Quixote (Coleção Temas de Educação, 39).

Oliveira, L.M.P. (2006) "Analisando a metodologia de mediação a distância da formação de educadores, à luz da perspectiva linguística sócio-histórica”, São Paulo: EDUC.

Papert, Seygmour (1997) “A máquina das crianças: Repensando a Escola na Era da Informática”, Porto Alegre: Artes Médicas.

Perrenoud, Philippe (2000) "10 novas competências para ensinar", Porto Alegre: Artmed.

Sancho, J. M. \& Hernandez, F. et al. (Org) (2006) "Tecnologias para Transformar a Educação", Porto Alegre: Artmed.

Valente, José Armando (1999) "Computadores e conhecimento: repensando a educação" Campinas, SP: UNICAMP/NIED. 